\title{
Uncertainty and the welfare economics of medical care: an Austrian rebuttal: part 1
}

\author{
Gilbert Berdine MD
}

Opponents of free market solutions to the scarcity of health care claim that health care is special and cannot be treated like a commodity. Kenneth Arrow is frequently cited as proof that special features of health care violate assumptions that free market economics are based on. An example can be found in a recent debate on a single payer solution to health care..$^{1-4}$ In their rebuttal, my opponents of free market solutions claimed:

"A free market for health care is not only undesirable: it is, as economists have noted for decades, a fantasy. Fundamentally, the degree of information asymmetry between the buyer (the patient) and the seller (the provider) prevents health care from conforming to the theoretical tenets of free-market economics. Kenneth Arrow famously contended that the uncertainty intrinsic to health care makes it unique from other goods and services."3

My opponents cited a famous work by Kenneth Arrow from 1963 titled: Uncertainty and the Welfare Economics of Medical Care. ${ }^{5}$ This article will examine the assumptions, logic and assertions of this paper by Kenneth Arrow. I hope to demonstrate that rather than proving anything, the paper is mostly unsubstantiated assertions many of which are clearly incorrect on the basis of common experience.

In his first section, Kenneth Arrow defines what he means by a free market, asserts that health care has special features incompatible with his definition of a free market, and concludes that various

Corresponding author: Gilbert Berdine MD Contact Information: Gilbert.Berdine@ttuhsc.edu DOI: 10.12746/swrccc2016.0416.221 uncertainties require non-market interventions, such as government subsidy, to achieve optimal or efficient results. Before considering Arrow's specific analysis, I would like to consider whether this general method is valid. Consider the following equation:

$$
\mathrm{PV}=\mathrm{nRT} \text {. }
$$

Every physician should recognize that this equation is the Ideal Gas Equation. There are no ideal gases in nature, so why do we bother learning about ideal gases that do not exist? The utility of the Ideal Gas Equation is that it leads to predictions about how gases behave. Whether or not computations based on the equation give answers that differ from actual measurements at the $6^{\text {th }}$ decimal point is not what determines the utility of the equation. The utility of the equation is that general principles are easy to grasp and the equation allows predictions that are good approximations of real gas behavior. The advanced student can learn the corrections for non-ideal behavior due to factors such as the non-zero volume of molecules. Demonstration that a real gas, such as oxygen, violates the assumptions of an ideal gas does not void the utility of the equation or its applicability to the behavior of oxygen. Likewise, a demonstration that a market for health care contains non-ideal features does not invalidate analysis based on ideal free markets. One would have to demonstrate that the deviations from ideal behavior are so great as to make qualitative predictions impossible.

The Austrian definition of a free market is that all exchanges are voluntary; no coercion is involved. While this definition may be violated by existing health care in the United States, such as the mandatory provisions of the Affordable Care Act (ACA), there is no intrinsic feature of health care that make Austrian free markets impossible in the United States. Only if 
one stipulates that health care is a right rather than a scarce resource can health care be considered to be incompatible with the Austrian definition of a free market. I will deal with that issue near the end of this discussion.

While the Austrian definition of a free market is very simple, Kenneth Arrow's definition is complicated. Arrow defines a free market based on a competitive model.

"The focus of discussion will be on the way the operation of the medical-care industry and the efficacy with which it satisfies the needs of society differ from a norm, if at all. The "norm" that the economist usually uses for the purposes of such comparisons is the operation of a competitive model ..."

Kenneth Arrow then defines a competitive model.

"that is, the flows of services that would be offered and purchased and the prices that would be paid for them if each individual in the market offered or purchased services at the going prices as if his decisions had no influence over them, and the going prices were such that the amounts of services which were available equaled the total amounts which other individuals were willing to purchase, with no imposed restrictions on supply or demand."

This definition appears to be a fantasy even for fungible commodities as the Law of Marginal Utility dictates that each transaction will affect the price. Be that as it may, Kenneth Arrow moves on to a discussion of Pareto Optimality.

"If a competitive equilibrium exists at all, and if all commodities relevant to costs or utilities are in fact priced in the market, then the equilibrium is necessarily optimal in the following precise sense (due to V. Pareto): There is no other allocation of resources to services which will make all participants in the market better off." 5

There are subtle differences between the Austrian and mainstream viewpoints. The mainstream view is that each transaction moves towards a Pareto Optimal point, while Austrians believe that each transaction clears the market at a Pareto Optimal point. The distinction is important, but it does not affect the discussion of this topic. Both viewpoints believe that the market achieves a condition in which all exchanges make all participants better off; there are neither unsatisfied buyers nor sellers. The following illustration should clarify this concept.

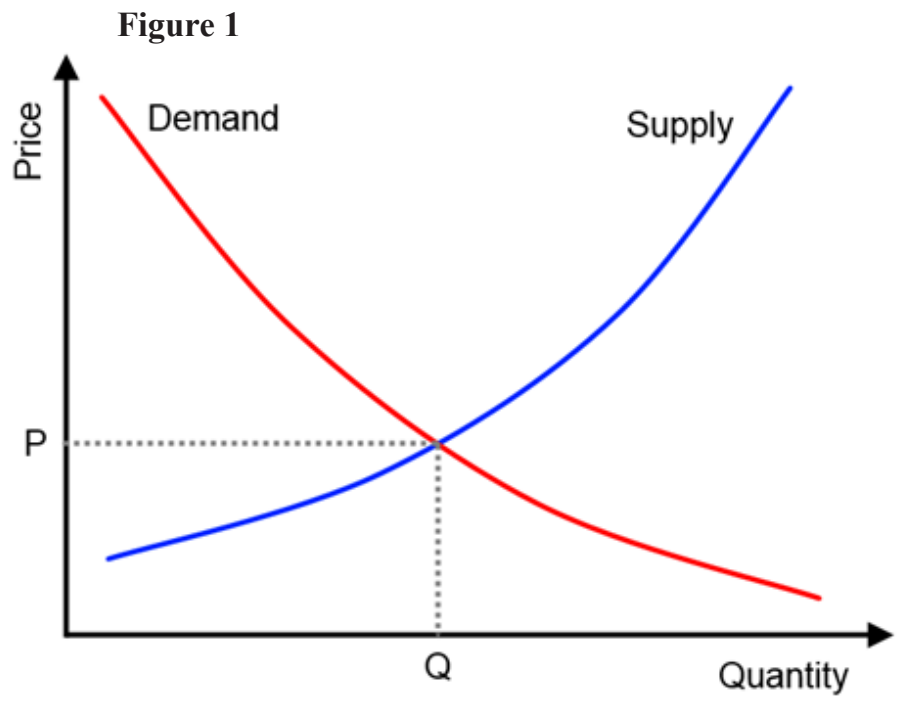

All schools of economics accept this figure. The supply curve has positive slope. As price increases more goods are offered for sale. The demand curve has negative slope. As price increases fewer bids for purchase will be extended. The two curves must intersect and the point of intersection is called the market clearing point or market clearing price. At the market clearing price there are neither unsatisfied buyers nor sellers. Note, however, that not everyone makes a purchase or sells something. Some buyers refuse to purchase because they value the price more than the good. In other words, they have a higher priority for the money. Some sellers decline to sell; they value the good more than the price. In other words, the good has a higher priority to them than anything else that the money could buy. Finally, at any price above or below the market clearing price, there would be unsatisfied buyers or sellers. At a price above the market clearing price, there are sellers willing to supply, but they cannot find a buyer at that price. At a price 
below the market clearing price, there are buyers willing to buy, but they cannot find a seller at that price.

The following text is probably the crux of the argument as it provides the justification for deviating from Pareto Optimality.

"It is reasonable enough to assert that a change in allocation which makes all participants better off is one that certainly should be made;" 5 This seems to be a tautology and irrefutable. However, Kenneth Arrow will disagree before the sentence is completed. "this is a value judgment, not a descriptive proposition, but it is a very weak one."

The above assertion that the value judgement of optimality is a weak one seems counterintuitive and is offered without any justification. Apparently Kenneth Arrow considered it to be self-evident.

"We cannot indeed make a change that does not hurt someone; but we can still desire to change to another allocation if the change makes enough participants better off and by so much that we feel that the injury to others is not enough to offset the benefit." 5

This is a rather bold assertion of how elites view Utilitarianism. Elites believe that it is acceptable to make others worse off as long as there is some benefit to a favored third party. The group being harmed is rarely if ever consulted about their opinion on the matter. We see this thinking with ACA. Healthy people have been mandated to subsidize the sick members of the group. The elites cannot understand why the healthy are not be happy with that arrangement which is why they failed to predict what was obvious to Austrians: ACA enrollment would be skewed towards high cost sick patients leading to losses by insurers and ever increasing premiums which would skew the enrollment even more. ${ }^{6}$

Kenneth Arrow then provides an intellectual justification for subsidies to achieve a desired distribution of health care.

"For any given distribution of purchasing power, the market will, under the assumptions made, achieve a competitive equilibrium which is necessarily optimal; and any optimal state is a competitive equilibrium corresponding to some distribution of purchasing power, so that any desired optimal state can be achieved." 5

It is true that the market clearing price depends on the initial distribution of goods and money. It is also true that different starting conditions will, in general, lead to a different market clearing price. It is far from clear, however, that any market clearing price and quantity can be achieved by rearranging the starting conditions. This is another assertion provided without any evidence or justification that, apparently, Kenneth Arrow considered to be self-evident.

"The redistribution of purchasing power among individuals most simply takes the form of money: taxes and subsidies. The implications of such a transfer for individual satisfactions are, in general, not known in advance. But we can assume that society can ex post judge the distribution of satisfactions and, if deemed unsatisfactory, take steps to correct it by subsequent transfers. Thus, by successive approximations, a most preferred social state can be achieved, with resource allocation being handled by the market and public policy confined to the redistribution of money income." 5

Here we have the Progressive policy of achieving desired market results through subsidies and taxes. Kenneth Arrow admits that the results of the policy will not be known in advance. That part of his paper seems to be conveniently ignored by opponents of the Free Market. Kenneth Arrow assumed, without any justification or proof, that each iteration would get progressively closer to the final goal. The reality is that each iteration of policy made things worse and the subsidies made health care less affordable for everyone. At the time - $1963-90 \%$ of senior citizens could afford to pay their total health care costs out of pocket. ${ }^{7}$ After 50 years of tweaking and adjusting subsidies through Medicare, Medicaid, Medicare Part D and ACA, nobody can afford health care in the United States. 
We see that Kenneth Arrow's prescription for a health care system that followed market principles would be the kinds of subsidies and taxes that were enacted with Medicare, Medicaid and ACA. It is ironic that the next section of the paper is purported to prove that the scarcity of health care cannot be most efficiently handled by the market, because that condition would require the government to become a direct provider of health care.

Kenneth Arrow concludes this introductory section with a discussion of risk and risk transfer.

"The instance of nonmarketability with which we shall be most concerned is that of risk-bearing. The relevance of risk-bearing to medical care seems obvious; illness is to a considerable extent an unpredictable phenomenon. The ability to shift the risks of illness to others is worth a price which many are willing to pay."5

Some clarification of this statement is necessary because many people now conflate insurance with subsidy. It is true that illness is unpredictable, but that does not make it a non-marketable commodity. While in some cases it is desirable to shift risk onto others, this is not the case for all aspects of health care. I do not know in advance when I will need a Band-Aid, but that does not prevent a robust market for Band-Aids from existing. The current price of Band-Aids is about 6 cents per Band-Aid, so I keep a box of them handy for future needs.

"Nevertheless, as we shall see in greater detail, a great many risks are not covered, and indeed the markets for the services of risk-coverage are poorly developed or nonexistent." 5

Kenneth Arrow maintains that the unavailability of health insurance for all people is proof that health care is not a marketable commodity and that markets cannot satisfactorily distribute health care. Continuing my Band-Aid example, it would be silly to expect insurance to cover Band-Aids as the cost of administering the program would be much greater than the cost of the Band-Aid. Malcolm Bird discovered this when he took his 1-year-old daughter to the emergency room (ER). ${ }^{8}$ The treatment consisted of cleaning the finger and applying a Band-Aid. The bill was $\$ 629$. The hospital justified the outrageous price as being "only" $\$ 7$ for the actual Band-Aid and over $\$ 400$ for the "service" fee. The $\$ 7$ charge for the Band-Aid was only 100 times the market price of a Band-Aid. Was the $\$ 400$ service fee reasonable? By comparison, Medicare allows a pulmonary specialist (me) \$139.58 for a level 5 (maximally complex) follow-up visit. There is a good reason that insurance does not cover Band-Aids and non-marketability has nothing to do with it.

Catastrophic yet unpredictable events are insurable and a robust insurance system existed before it was systematically destroyed by mandatory expansion of coverage to uninsurable conditions. Motor vehicle accidents are, for the most part, unpredictable. Developing acute leukemia is unpredictable. These very expensive events can be insured for pennies on the dollar because people are willing to accept risks on an actuarially sound basis that generates a profit by covering large numbers of people when only a small number will require a claim to be paid. The insurer accepts the average expected cost plus a profit; the insured makes a payment that is a premium to the actual risk.

The insured willingly pay the premium to the risk for two reasons. The first is that they are not required to set aside the large cost of treatment in the event of a disaster. In the case of the Band-Aid, the cost is low, so people just set that cost aside to be prepared, but this is not practical for rare and catastrophic events. The second reason is that buying insurance ahead of time avoids the problem of having a very poor bargaining position when you are in urgent need of a service. Your negotiating position to purchase health care is much more advantageous when you do not need it at the moment. Insurance avoids the problem of price gouging when emergencies arise.

Insurance can only cover insurable events. Not all health care services are insurable. Pre-existing conditions are not insurable. If someone has end stage renal disease, their health care has predictable 
costs each year for dialysis and routine care. Nobody will accept a transfer of risk for pennies on the dollar. It is not uncertainty that makes pre-existing conditions uninsurable; rather it is the certainty of costs that make the pre-existing condition uninsurable. The unavailability of insurance has nothing to do with marketability.

Routine health maintenance is not insurable. These are certain costs. The annual check-up, the screening colonoscopy at age 50 , screening mammograms are all examples of predictable events. The only way to pay for these is by saving prior to when these predictable events occur. Again, it is not uncertainty that makes health maintenance uninsurable. Programs that "cover" pre-existing conditions and routine health maintenance are subsidies rather than insurance programs. All subsidies have the inevitable and unintended side effect of increasing the cost of health care for everyone. ${ }^{2}$

Subjective complaints are not insurable for a different reason. Death, dismemberment, disfigurement, and the contraction of many diseases are objective events. A third party can verify or deny that the condition is present. Subjective complaints such as pain, fatigue, or malaise are not insurable. There is no way to verify or deny that the complaint is present. Without the ability to objectively verify the validity of a claim, it would be impossible to enforce any insurance contract.

"... briefly, it is impossible to draw up insurance policies which will sufficiently distinguish among risks, particularly since observation of the results will be incapable of distinguishing between avoidable and unavoidable risks."

What is meant by avoidable risks? Events that are voluntary actions are not insurable. Life insurance cannot cover suicide. Fire insurance cannot cover arson. The reason these situations are not insurable has nothing to do with morality. The risk of voluntary actions cannot be determined on an actuarial basis. The voluntary nature of the event transforms an uncertainty into a certainty.
Kenneth Arrow concludes this introductory section with a statement about uncertainty with which this paper has generally been associated:

"I will hold that virtually all the special features of this industry, in fact, stem from the prevalence of uncertainty."

Part 2 will be in the January 2017 issue.

Author Affiliation: Dr. Gilbert Berdine is a pulmonary physician in the Department of Internal Medicine, TTUHSC.

Received: 8/18/2016

Accepted: 10/7/2016

Published electronically: 10/15/2016

\section{References}

1. Gaffney AW, Verhoef P, Hall JB. Point: Should pulmonary/ ICU physicians support single-payer health-care reform? Yes. Chest 2016; 150(1):10-11.

2. Berdine, Gilbert G. Counterpoint: Should pulmonary/ICU physicians support single-payer health-care reform? No. Chest 2016; 150(1):11-14.

3. Gaffney AW, Verhoef P, Hall JB. Rebuttal from Drs Gaffney, Verhoef, and Hall. Chest 2016; 150(1)]:14-15.

4. Rebuttal from Dr Berdine. Chest 2016; 150(1):15-16.

5. Arrow KJ. Uncertainty and the welfare economics of medical care. Am Econ Rev 1963; 53(5):941-973.

6. Berdine G. The Supreme Court decision on Obama care part ii: the unintended consequences on the already insured. Southwest Respiratory and Critical Care Chronicles 2013; 1(3):22-24. doi: 10.12746/swrecc2013.0103.029

7. Langford E. Medical Care Costs for the Aged: First Findings of the 1963 Survey of the Aged. [about 6 p.]. Available from: https://www.ssa.gov/policy/docs/ssb/v27n7/v27n7p3.pdf 8. Rousseau S. A band-aid can cost $\$ 629$ in America and other facts. Available from: http://digg.com/2016/expensive-bandaid-us-healthcare 